\title{
New exact and numerical solutions for the effect of suction or injection on flow of nanofluids past a stretching sheet
}

https://doi.org/10.1515/nleng-2017-0059

Received May 9, 2017; revised February 15, 2017; accepted February 7,2018

Abstract: The flow of nanofluids past a stretching sheet has attracted much attention due to its wide applications in industry and engineering. Theoretical and numerical solutions have been discussed in this paper for studying the effect of suction or injection on flow of nanofluids past a stretching sheet. In the absence of thermophoresis the analytical exact solution of the stream function was obtained in terms of exponential function, while the exact solutions for temperature and nanoparticle volume fraction were obtained in terms of the generalized incomplete gamma function. In addition, in the presence of thermophoresis, the exact solutions are not available. Therefore, the numerical results, carried out by using Chebyshev collocation method (ChCM). It is found that a good agreement exists between the present results and with those published works. Useful results for temperature profile, concentration profile, reduced Nusselt number and reduced Sherwood number are discussed in details graphically. It was also demonstrated that both temperature and concentration profiles decrease by an increase from injection to suction. Finally, the present results showed that increase of the wall mass transfer from injection to suction decreased both reduced Nusselt number and the reduced Sherwood number when Brownian motion parameter and Lewis number increased.

Keywords: Nanofluids; Stretching sheet; Boundary layer; Analytical and Numerical solutions; Suction or injection; New analytical and Numerical solutions

\footnotetext{
*Corresponding Author: Nader Y. Abd Elazem, Department of Mathematics, Faculty of Science, University of Tabuk, P.O. Box 741, Tabuk 71491, Saudi Arabia, E-mail: naderelnafrawy@yahoo.com, nelnafrawy@ut.edu.sa
}

\section{Introduction}

Nanotechnology has been widely used in industry since materials with sizes of nanometers possess unique physical and chemical properties. Nanotechnology is considered by many to be one of the significant forces that drive the next major industrial revolution of this century. Nanoscale particle added fluids are called as nanofluid. It represents the most relevant technological cutting edge currently being explored. It aims at manipulating the structure of the matter at the molecular level with the goal for innovation in virtually every industry and public endeavor including biological sciences, physical sciences, electronics cooling, transportation, the environment and national security. Choi [1] is the first author to use the term nanofluid which refers to the fluid with suspended nanoparticles. In [2], the author proved that the addition of small amount less than $1 \%$ by volume of nanoparticles to conventional heat transfer liquids increased the thermal conductivity of the fluid up to approximately two times. Each of the authors [3], [4], [5] and [6] reported that with low nanoparticles concentrations (1-5 Vol \%), the thermal conductivity of the suspensions can increase more than $20 \%$. In recent years, some interest has been given to the study of the boundary layer flow of a nanofluid and some useful results have been introduced by the authors Kakac and Pramuanjaroenkij [7], Abu-Nada [8], Oztop and AbuNada [9], Nield and Kuznetsovand [10], and Kuznetsov and Nield [11]. The exact resolution for the flow over a stretching sheet with suction and injection effect has been reported by Gupta and Gupta [12]. The aim of the present paper is to extend the work of Khan and Pop [13] for studying the effect of suction or injection on flow of nanofluids past a stretching sheet, where new analytical and numerical results are deduced at some values of the investigating physical parameters. The present exact solutions can be found easily in terms of exponential and generalized incomplete gamma functions at some new values of the physical parameters. They are then validated and plotted by using Chebyshev Collocation Method (ChCM). 


\section{Analysis}

A similarity transform is applied in Khan and Pop [13] to convert the basic steady conservation of mass, momentum, thermal energy and nanoparticales equations for nanofluids into nonlinear ordinary differential equations and given by:

$$
\begin{gathered}
f^{\prime \prime \prime}+f f^{\prime \prime}-\left(f^{\prime}\right)^{2}=0, \\
\frac{1}{\operatorname{Pr}} \theta^{\prime \prime}+f \theta^{\prime}+N b \phi^{\prime} \theta^{\prime}+N t\left(\theta^{\prime}\right)^{2}=0, \\
\phi^{\prime \prime}+\text { Lef } \phi^{\prime}+\frac{N t}{N b} \theta^{\prime \prime}=0,
\end{gathered}
$$

with the boundary conditions:

$$
\begin{gathered}
f(0)=s, \quad f^{\prime}(0)=1, \quad \theta(0)=1, \quad \phi(0)=1, \\
f^{\prime}(\infty)=0, \quad \theta(\infty)=0, \quad \phi(\infty)=0,
\end{gathered}
$$

where primes denote to differentiation with respect to $\eta$ and $\mathrm{Pr}, \mathrm{Nb}, \mathrm{Nt}$ and $\mathrm{Le}$ are Prandtl number, Brownian motion parameter, thermophoresis parameter and Lewis number, respectively. Moreover, $f, \theta$ and $\phi$ are the dimensionless of the stream function, temperature and nanoparticle volume fraction, respectively. When $s=0$, i.e. with no effect of the suction or injection parameter, the system (1) - (5) is reached to that one obtained in [13]. Furthermore, the exact solution of Eq. (1) subject to the boundary conditions in (4) - (5) is already well known and investigated by Crane [14] as:

$$
f(\eta)=1-e^{-\eta}
$$

In the case of $s \neq 0$, i.e. with effect of the suction or injection parameter, assuming the solution in the form

$$
f(\eta)=a+b e^{-\beta \eta}
$$

Substituting Eq. (7) into Eq. (1) and in view of the boundary conditions given in (4) - (5), the exact solution of Eq. (1) becomes:

$$
\begin{gathered}
f(\eta)=s+\frac{d}{\beta}\left(1-e^{-\beta \eta}\right), \\
a=s+\frac{d}{\beta}, b=-\frac{d}{\beta}, \beta=\frac{1}{2}\left(s+\sqrt{s^{2}+4 d}\right),
\end{gathered}
$$

where $d=1$ denotes stretching sheet. Then, the system (1)-(5) reduces to the following ordinary differential equations:

$\theta^{\prime \prime}(\eta)+\operatorname{Pr}\left[s+\frac{d}{\beta}\left(1-e^{-\beta \eta}\right)+N b \phi^{\prime}(\eta)\right] \theta^{\prime}(\eta)+\operatorname{Pr} N t\left[\theta^{\prime}(\eta)\right]^{2}=0$,

$$
\phi^{\prime \prime}(\eta)+L e\left[s+\frac{d}{\beta}\left(1-e^{-\beta \eta}\right)\right] \phi^{\prime}(\eta)+\frac{N t}{N b} \theta^{\prime \prime}(\eta)=0,
$$

where the boundary conditions on $\theta(\eta)$ and $\phi(\eta)$ are given in (4) - (5). Further, as in Kuznetsov and Nield [11], the quantities of practical interest in this study are the reduced Nusselt number Nur and the reduced Sherwood number Shr which are defined respectively by

$$
\text { Nur }=-\theta^{\prime}(0), \quad \text { Shr }=-\phi^{\prime}(0) .
$$

\subsection{Exact solutions for special cases at $\mathrm{Nt}=0$}

In this subsection, prospect of getting exact solutions for the present governing equations, i.e. the system (1) - (5), at several particular values of the physical parameters are used for this purpose.

\subsubsection{Case $I:$ at $N b=0$}

In this case, substituting Eq. (7) into the system (9 10) simplifies to a single boundary value problem for $\theta(\eta)$ while the boundary value problem for $\phi(\eta)$ leads to ill-posed and is of no physical significance. The boundary value problem for $\theta(\eta)$ becomes:

$$
\theta^{\prime \prime}(\eta)+\operatorname{Pr}\left[s+\frac{d}{\beta}\left(1-e^{-\beta \eta}\right)\right] \theta^{\prime}(\eta)=0 .
$$

In order to solve Eq. (12), by using separation method and carry out integration twice w.r.t. $\eta$ from 0 to $\eta$, yields

$\theta(\eta)=\theta(0)+\theta^{\prime}(0) e^{\operatorname{Pr} \frac{\delta}{\beta}} \int_{0}^{\eta} e^{-\operatorname{Pr}(s+\delta) \sigma} e^{-\operatorname{Pr} \frac{\delta}{\beta} e^{-\beta \sigma}} d \sigma, \delta=\frac{d}{\beta}$.

Applying the condition $\theta(0)=1$, Eq. (13) becomes:

$$
\theta(\eta)=1+\theta^{\prime}(0) e^{\operatorname{Pr} \frac{\delta}{\beta}} \int_{0}^{\eta} e^{-\operatorname{Pr}(s+\delta) \sigma} e^{-\operatorname{Pr} \frac{\delta}{\beta} e^{-\beta \sigma}} d \sigma .
$$

Assuming that $\gamma=\operatorname{Pr} \frac{\delta}{\beta} e^{-\beta \sigma}$, the integration in Eq. (14) can be analytically converted in terms of a well-known special function as:

$$
\begin{aligned}
& \int_{0}^{\eta} e^{-\operatorname{Pr}(s+\delta) \sigma} e^{-\operatorname{Pr} \frac{\delta}{\beta} e^{-\beta \sigma}} d \sigma \\
& =\left(\frac{1}{\beta}\right)\left(\frac{\beta}{\operatorname{Pr} \delta}\right)\left(\operatorname{Pr} \frac{s+\delta}{\beta}\right) \int_{\operatorname{Pr} \frac{\delta}{\beta} e^{-\beta \eta}}^{\operatorname{Pr} \frac{\delta}{\beta}} \gamma^{\left(\operatorname{Pr} \frac{s+\delta}{\beta}-1\right)} e^{-\gamma} d \gamma .
\end{aligned}
$$


Using the definition of the generalized incomplete gamma function

$$
\Gamma\left(a, z_{0}, z_{1}\right)=\int_{z_{0}}^{z_{1}} \gamma^{a-1} e^{-\gamma} d \gamma
$$

we can rewrite Eq. (14) as:

$$
\begin{gathered}
\theta(\eta)=1+\theta^{\prime}(0) e^{\operatorname{Pr} \frac{\delta}{\beta}}\left(\frac{1}{\beta}\right)\left(\frac{\beta}{\operatorname{Pr} \delta}\right)^{\left(\operatorname{Pr} \frac{s+\delta}{\beta}\right)} \\
\Gamma\left(\operatorname{Pr} \frac{s+\delta}{\beta}, \operatorname{Pr} \frac{\delta}{\beta} e^{-\beta \eta}, \operatorname{Pr} \frac{\delta}{\beta}\right)
\end{gathered}
$$

Inserting the boundary condition $\phi(\infty)=0$ in Eq. (17), we obtain

$$
\theta^{\prime}(0)=-\frac{(1 / \lambda)}{\Gamma\left(\operatorname{Pr} \frac{s+\delta}{\beta}, 0, \operatorname{Pr} \frac{\delta}{\beta}\right)}, \lambda=\left(\frac{e^{\operatorname{Pr} \frac{\delta}{\beta}}}{\beta}\right)\left(\frac{\beta}{\operatorname{Pr} \delta}\right)^{\left(\operatorname{Pr} \frac{s+\delta}{\beta}\right)}
$$

Substituting Eq. (18) into Eq. (17), we get the exact solution of the temperature distribution in terms of the generalized incomplete gamma function in a simpler form at any Prandtl number Pr:

$$
\theta(\eta)=\frac{\Gamma\left(\operatorname{Pr} \frac{s+\delta}{\beta}, 0, \operatorname{Pr} \frac{s}{\beta}\right)-\Gamma\left(\operatorname{Pr} \frac{s+\delta}{\beta}, \operatorname{Pr} \frac{\delta}{\beta} e^{-\beta \eta}, \operatorname{Pr} \frac{\delta}{\beta}\right)}{\Gamma\left(\operatorname{Pr} \frac{s+\delta}{\beta}, 0, \operatorname{Pr} \frac{\delta}{\beta}\right)} .
$$

The reduced Nusselt number has the exact value :

$$
\text { Nur }=-\theta^{\prime}(0)=\frac{(1 / \lambda)}{\Gamma\left(\operatorname{Pr} \frac{s+\delta}{\beta}, 0, \operatorname{Pr} \frac{\delta}{\beta}\right)} .
$$

\subsubsection{Case $I I:$ at $N b \neq 0$}

The system $(9-10)$ simplifies to two coupled ordinary differential equations at $N t=0$ :

$$
\begin{gathered}
\theta^{\prime \prime}(\eta)+\operatorname{Pr}\left[s+\frac{d}{\beta}\left(1-e^{-\beta \eta}\right)+N b \phi^{\prime}(\eta)\right] \theta^{\prime}(\eta)=0, \\
\phi^{\prime \prime}(\eta)+L e\left[s+\frac{d}{\beta}\left(1-e^{-\beta \eta}\right)\right] \phi^{\prime}(\eta)=0 .
\end{gathered}
$$

In order to solve the equation (21) must be found $\phi(\eta)$ and that the integration of the equation (22) twice w.r.t. $\eta$ and using the equations (4-5) following the same steps of the first case, then

$$
\begin{gathered}
\phi(\eta)=1+\phi^{\prime}(0) e^{L e \frac{\delta}{\beta}}\left(\frac{1}{\beta}\right)\left(\frac{\beta}{L e \delta}\right)^{\left(L e \frac{s+\delta}{\beta}\right)} \\
\Gamma\left(L e \frac{s+\delta}{\beta}, L e \frac{\delta}{\beta} e^{-\beta \eta}, L e \frac{\delta}{\beta}\right)
\end{gathered}
$$

Using the boundary condition $\phi(\infty)=0$, we get

$$
\phi^{\prime}(0)=-\frac{(1 / \varpi)}{\Gamma\left(L e \frac{s+\delta}{\beta}, 0, L e \frac{\delta}{\beta}\right)}, \varpi=\left(\frac{e^{L e \frac{\delta}{\beta}}}{\beta}\right)\left(\frac{\beta}{L e \delta}\right)^{\left(L e \frac{s+\delta}{\beta}\right)} .
$$

Hence, the exact solution for $\phi(\eta)$ in a simpler form as:

$$
\phi(\eta)=\frac{\Gamma\left(L e \frac{s+\delta}{\beta}, 0, L e \frac{\delta}{\beta} e^{-\beta \eta}\right)}{\Gamma\left(L e \frac{s+\delta}{\beta}, 0, L e \frac{\delta}{\beta}\right)} .
$$

Inserting Eq. (25) into Eq. (21) and in the same procedure made above, we get $\theta(\eta)$ in a closed analytical form as:

$$
\theta(\eta)=1-\frac{\int_{0}^{\eta} e^{-\operatorname{Pr}\left[(s+\delta) \sigma+\frac{\delta}{\beta} e^{-\beta \sigma}+N b\left(\frac{\Gamma\left(L e \frac{s+\delta}{\beta}, 0, L e \frac{\delta}{\beta} e^{-\beta \sigma}\right)}{\Gamma\left(L e \frac{s+\delta}{\beta}, 0, L e \frac{\delta}{\beta}\right)}\right)\right]} d \sigma}{\int_{0}^{\infty} e^{-\operatorname{Pr}\left[(s+\delta) \sigma+\frac{\delta}{\beta} e^{-\beta \sigma}+N b\left(\frac{\Gamma\left(L e \frac{s+\delta}{\beta}, 0, L e \frac{\delta}{\beta} e^{-\beta \sigma}\right)}{\Gamma\left(L e \frac{s+\delta}{\beta}, 0, L e \frac{\delta}{\beta}\right)}\right)\right]} d \sigma} .
$$

The reduced Nusselt number Nur and the reduced Sherwood number $S h r$ have the exact form:

$$
\begin{aligned}
& \text { Nur }=\frac{e^{-\operatorname{Pr}(1+N b)}}{\int_{0}^{\infty} e^{-\operatorname{Pr}\left[(s+\delta) \sigma+\frac{\delta}{\beta} e^{-\beta \sigma}+N b\left(\frac{\Gamma\left(L \frac{S+\delta}{\beta}, 0, L e \frac{\delta}{\beta} e^{-\beta \sigma}\right)}{\Gamma\left(L e \frac{s+\delta}{\beta}, 0, L e \frac{\delta}{\beta}\right)}\right)\right]} d \sigma}, \\
& S h r=\frac{\beta e^{-L e \frac{\delta}{\beta}\left(\frac{\beta}{L e \delta}\right)^{-\left(L e \frac{s+\delta}{\beta}\right)}}}{\Gamma\left(L e \frac{S+\delta}{\beta}, 0, L e \frac{\delta}{\beta}\right)} .
\end{aligned}
$$

\subsubsection{Case III: at $\mathrm{Nb} \neq 0$ and $\mathrm{Pr}=\mathrm{Le}=1$}

The exact expression for $\phi(\eta)$ in a simpler form in this case is given by

$$
\phi(\eta)=\frac{\Gamma\left(\frac{s+\delta}{\beta}, 0, \frac{\delta}{\beta} e^{-\beta \eta}\right)}{\Gamma\left(\frac{s+\delta}{\beta}, 0, \frac{\delta}{\beta}\right)} .
$$

By putting $P r=L e=1$ in Eq.(26), becomes:

$$
\theta(\eta)=\frac{1-e^{-N b \phi(\eta)}}{1-e^{-N b}}
$$

where,

$$
\begin{gathered}
\int_{0}^{\eta} e^{-\operatorname{Pr}\left[(s+\delta) \sigma+\frac{\delta}{\beta} e^{-\beta \sigma}+N b\left(\frac{\Gamma\left(L e \frac{S+\delta}{\beta}, 0, L e \frac{\delta}{\beta} e^{-\beta \sigma}\right)}{\Gamma\left(L e \frac{S+\delta}{\beta}, 0, L e \frac{\delta}{\beta}\right)}\right)\right]} d \sigma \\
=\frac{\xi}{N b \beta}\left[e^{-N b \phi(\eta)}-e^{-N b}\right], \\
\int_{0}^{\infty} e^{-\operatorname{Pr}\left[(s+\delta) \sigma+\frac{\delta}{\beta} e^{-\beta \sigma}+N b\left(\frac{\Gamma\left(L e \frac{S+\delta}{\beta}, 0, L e \frac{\delta}{\beta} e^{-\beta \sigma}\right)}{\Gamma\left(L e \frac{S+\delta}{\beta}, 0, L e \frac{\delta}{\beta}\right)}\right)\right]} d \sigma \\
=\frac{\xi}{N b \beta}\left[1-e^{-N b}\right], \\
\xi=\left(\frac{\delta}{\beta}\right)^{-\left(\frac{s+\delta}{\beta}\right)} \Gamma\left(\frac{s+\delta}{\beta}, 0, \frac{\delta}{\beta}\right) .
\end{gathered}
$$


Therefore, the exact values of the reduced Nusselt number Nur and the reduced Sherwood number Shr are given respectively by

$$
N u r=\frac{\beta}{\xi} \frac{N b e^{-(1+N b)}}{1-e^{-N b}}, S h r=\frac{\beta}{\xi} e^{-\frac{\delta}{\beta}} .
$$

\subsection{Numerical}

In the presence of thermophoresis parameter, the exact solutions are not available. As described in the literature review, Canuto et al. [15] and Peyret [16], Chebyshev collocation method (ChCM) can be considered as a suitable choice for many practical problems. Therefore, Eqs. (1) - (3) with the boundary conditions (4) and (5) have been solved numerically by applying Chebyshev collocation method (see Refs. [17] and [18]).

\section{Results and Discussion}

Eqs. (1) - (3) with the boundary conditions (4) and (5) have been solved analytically in the absence of thermophoresis parameter where the exact solutions are available. Also, in the presence of thermophoresis parameter, the exact solutions are not available. Therefore, these equations carried out numerically, by using Chebyshev Collocation Method (ChCM). Table 1 shows comparison of the present exact and numerical results with Khan and Pop [13] and others for the reduced Nusselt number $-\theta^{\prime}(0)$ at $N b=N t=0$ for various values of $\operatorname{Pr}$. The present exact and numerical results show good agreement for various values of Pr. So, the present results are very accurate. In Tables 2 and 3 the numerical results are compared with Khan and Pop [13] for the reduced Nusselt number Nur $=-\theta^{\prime}(0)$ and the reduced Sherwood number $S h r=-\phi^{\prime}(0)$ at $\operatorname{Pr}=L e=10$, $N b=0.1,0.3,0.5$ for various values of $N t$. It is noted that the reduced Nusselt number Nur $=-\theta^{\prime}(0)$ is a decreasing function, and vice versa the reduced Sherwood number $S h r=-\phi^{\prime}(0)$ is an increasing function.

Fig. $1(a, b, c)$ shows the exact solution of the effect of $\operatorname{Pr}$ and $s$ (injection) new parameters on the profiles of $\theta(\eta)$ and $-\theta^{\prime}(0)$ view at various values of $\mathrm{Pr}=$ $1,2,3,5,10$ and $s=-12,-7,-3$ when $N t=N b=$ $0, d=1$. These profiles of $\theta(\eta)$ as shown as in Fig. 1 (a) decrease with the increase in $\operatorname{Pr}$ and $s$ (injection) for the regions $(0 \leq \eta \leq 35,30 \leq \eta \leq 80,65 \leq \eta \leq$ 130) and increase in other regions $(0 \leq \eta \leq 10,20 \leq$ $\eta \leq 30,45 \leq \eta \leq 65)$. However, $\eta_{\infty}$ increase with the increase in $\operatorname{Pr}$ and $s=-12,-7,-3$ (injection). While
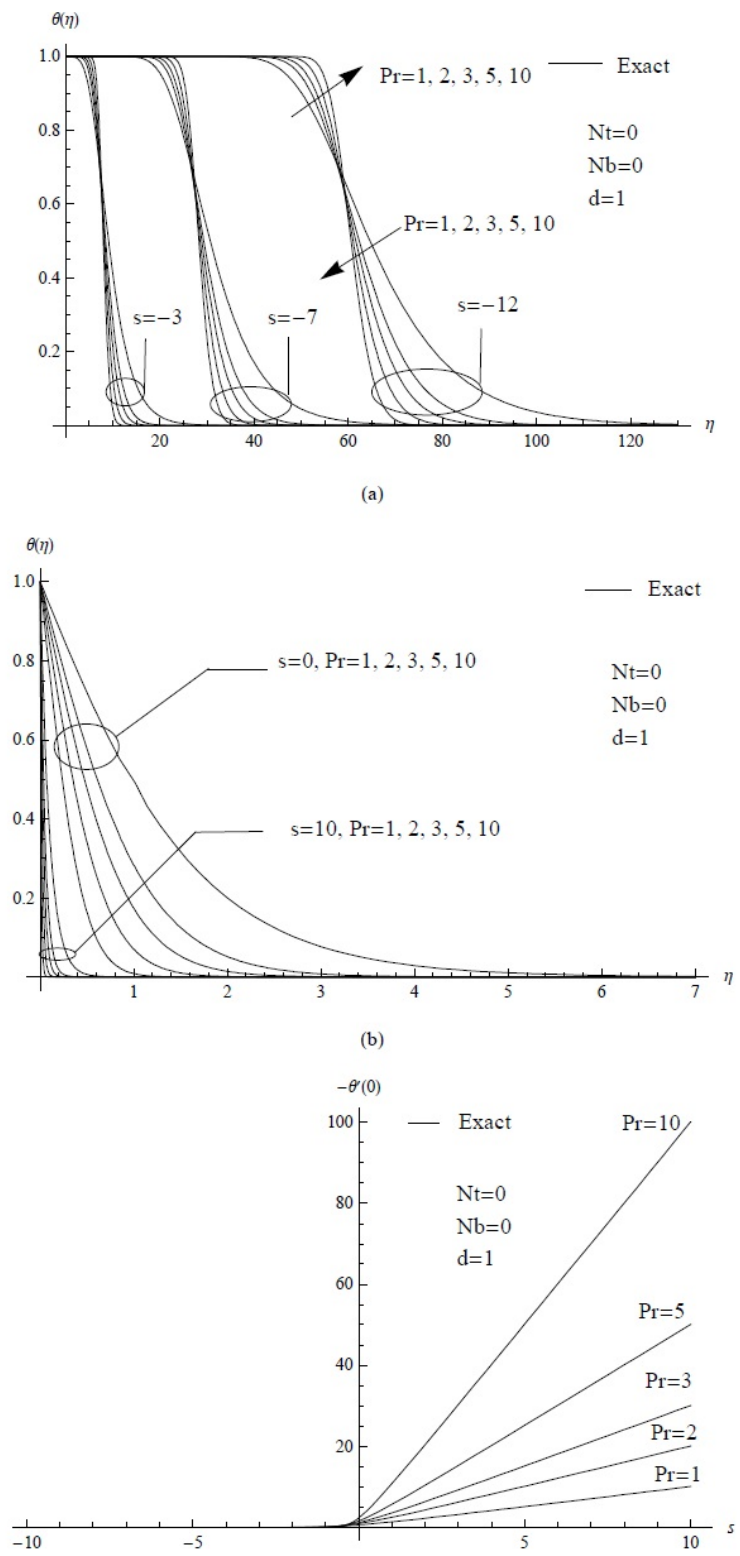

Fig. 1: Effect of $s$ and $\operatorname{Pr}$ in (a) and (b) on $\theta(\eta)$ and in (c) on $-\theta^{\prime}(0)$.

Table 1: Comparison with Khan and Pop [13] and others for the reduced Nusselt number- $\theta^{\prime}(0)$ when $N b=N t=0$ at various values of $\operatorname{Pr}$

\begin{tabular}{cccccc}
\hline$\eta$ & {$[13]$} & {$[19]$} & {$[20]$} & $\begin{array}{c}\text { Present } \\
\text { exact new solution }\end{array}$ & $\begin{array}{c}\text { Present } \\
(\text { ChCM })\end{array}$ \\
\hline 0.07 & 0.0663 & 0.0656 & 0.0656 & 0.0655625 & 0.0656346592 \\
0.20 & 0.1691 & 0.1691 & 0.1691 & 0.169089 & 0.1691091033 \\
0.70 & 0.4539 & 0.4539 & 0.5349 & 0.453916 & 0.4539163196 \\
2.00 & 0.9113 & 0.9114 & 0.9114 & 0.911358 & 0.9113442728 \\
7.00 & 1.8954 & 1.8954 & 1.8905 & 1.8954 & 1.8954000000 \\
20.0 & 3.3539 & 3.3539 & 3.3539 & 3.3539 & 3.3538204732 \\
70.0 & 6.4621 & 6.4622 & 6.4622 & 6.4622 & 6.4608249915 \\
\hline
\end{tabular}


Table 2: Numerical comparison with Khan and Pop [13] for the reduced Nusseltnumber Nur $=-\theta^{\prime}(0)$ when $\mathrm{Pr}=L e=10$, $N b=0.1,0.3,0.5$ at various values of $N t$.

\begin{tabular}{cccc}
\hline & \multicolumn{3}{c}{ Khan and Pop [13] } \\
$N t$ & $N b=0.1$ & $N b=0.3$ & $N b=0.5$ \\
\hline 0.1 & 0.9524 & 0.2522 & 0.0543 \\
0.2 & 0.6932 & 0.1816 & 0.0390 \\
0.3 & 0.5201 & 0.1355 & 0.0291 \\
0.4 & 0.4026 & 0.1046 & 0.0225 \\
0.5 & 0.3211 & 0.0833 & 0.0179 \\
\hline \multicolumn{3}{c}{ Present $($ ChCM) } \\
& $N b=0.1$ & $N b=0.3$ & $N b=0.5$ \\
\hline 0.1 & 0.9524119460 & 0.2521426678 & 0.0542159666 \\
0.2 & 0.6932178385 & 0.1816064648 & 0.0390571578 \\
0.3 & 0.5201734662 & 0.1355004643 & 0.0291005428 \\
0.4 & 0.4027809488 & 0.1046091201 & 0.0225030712 \\
0.5 & 0.3211622785 & 0.0833868494 & 0.0179057802 \\
\hline
\end{tabular}

Table 3: Numerical comparison with Khan and Pop [13] for the reduced Sherwood number Shr $=-\phi^{\prime}(0)$ when $P r=L e=10$, $N b=0.1,0.3,0.5$ at various values of $N t$

\begin{tabular}{cccc}
\hline & \multicolumn{3}{c}{ Khan and Pop [13] } \\
$N t$ & $N b=0.1$ & $N b=0.3$ & $N b=0.5$ \\
\hline 0.1 & 2.1294 & 2.4100 & 2.3836 \\
0.2 & 2.2740 & 2.5150 & 2.4468 \\
0.3 & 2.5286 & 2.6088 & 2.4984 \\
0.4 & 2.7952 & 2.6876 & 2.5399 \\
0.5 & 3.0351 & 2.7519 & 2.5731 \\
\hline \multicolumn{3}{c}{ Present $($ ChCM $)$} \\
\multicolumn{5}{c}{$N b=0.3$} \\
\hline 0.1 & 2.1239556223 & 2.4090539641 & 2.3836000000 \\
0.2 & 2.2736621591 & 2.5151218954 & 2.4468041119 \\
0.3 & 2.5286795613 & 2.6043029831 & 2.4984000000 \\
0.4 & 2.7959045377 & 2.6871897858 & 2.5403913241 \\
0.5 & 3.0219004569 & 2.7504708384 & 2.5482379801 \\
\hline
\end{tabular}

these profiles of $\theta(\eta)$ decrease with the increase in $\operatorname{Pr}$ and $s=0,10$ (suction) without variety in the temperature as in Fig. $1(b)$. In Fig. $1(c)$,for injection case, there are no observable effect for $s$ on the reduced Nusselt number Nur $=-\theta^{\prime}(0)$ when $s \leq-1$. However, for $s>-1$ the reduced Nusselt number Nur $=-\theta^{\prime}(0)$ begins to increase with increasing in $s$ and $\mathrm{Pr}$.

Fig. $2(a, b)$ illustrates the present new exact and numerical results for the effect of $s=-1,0,1$ on $\theta(\eta)$ and $\phi(\eta)$ in the case of $N t=0, P r=L e=1, d=1$ for $(a) N b=$ 0.1 and $(b) N b=0.5$. It is shown that the typical identical of these two type of solutions at $s=-1,0,1$ which reveal that the numerical Chebyshev collocation method (ChCM) is really effective and very accurate in studying the similar problems. Moreover, these profiles decrease with
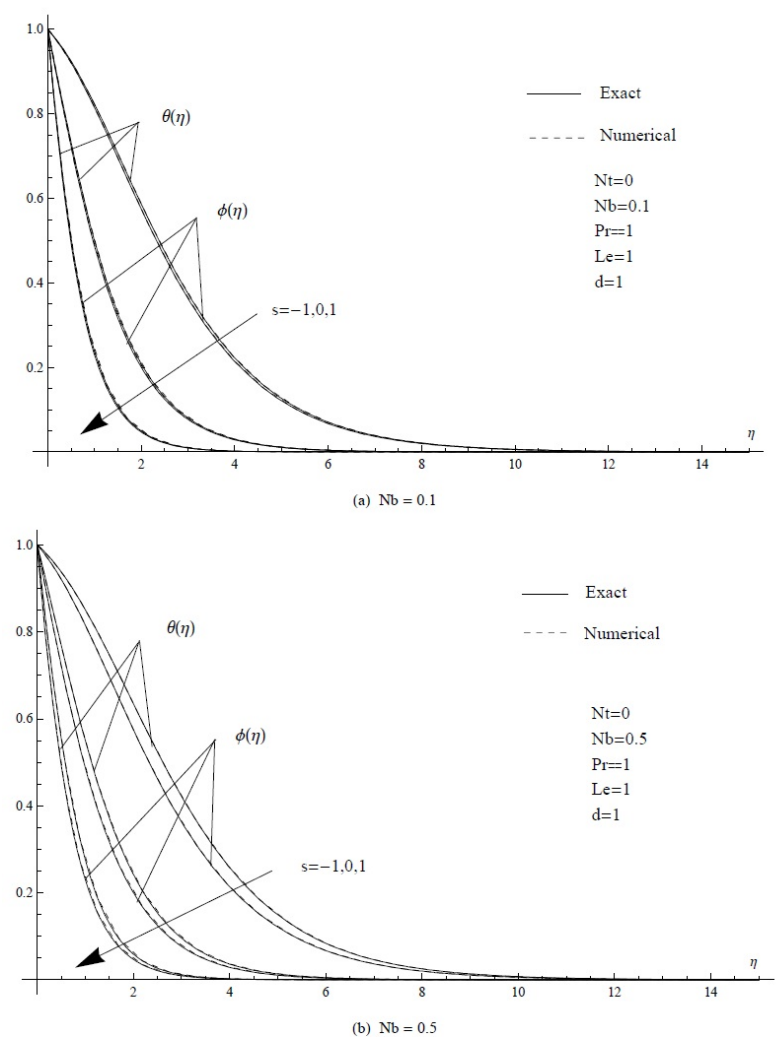

Fig. 2: Effect of $s$ on $\theta(\eta)$ and $\phi(\eta)$.

the increase in $s$. It is noted also that at $N b=0.5 \theta(\eta)$ is a slightly bigger than $\phi(\eta)$. The exact and numerical results of the profiles of $\phi(\eta)$ are presented in Fig. 3 for $(a) L e=$ 1, 2, 5, 10 at $N t=0, N b=0.1, s=1, P r=10$ and $d=1$, and $(b) N b=0.1,0.2,0.3,0.4,0.5$ at $N t=0, N b=$ $0.1, s=1, P r=L e=10$ and $d=1$. It is clear that the concentration function increases with increasing in the $L e$ as shown in in Fig. $3(a)$. Besides the typical matching of the exact and numerical solutions at given values of $L e$ and $N b$.It should be noted that in Fig. $3(b)$ there is no effect of $N b$ (see, Eq. 25). Fig. $4(a, b)$ indicates that the reduced Nusselt number Nur $=-\theta^{\prime}(0)$ and the reduced Sherwood number $S h r=-\phi^{\prime}(0)$ decrease with the increase in both $(a) s$ and $N b$ at $N t=0, P r=L e=1$ and $d=1$, and (b) $s$ and $L e$ at $N t=0, N b=0.1, \operatorname{Pr}=1$ and $d=$ 1 , where, for injection case, there are no observable effect for $s$ the reduced Sherwood number $S h r=-\phi^{\prime}(0)$ when $s \leq-1$. Fig. $5(a, b)$ depicts the numerical solutions for $\theta(\eta)$ and $\phi(\eta)$ for $(a)$ at different values of $s, N t$ when $N b=0.1, P r=L e=10$ and $d=1$ and $(b)$ at different values of $s, N b$ when $N t=0.1, P r=L e=10$ and $d=1$. It is known that an increase in $N t$, the temperature profile $\theta(\eta)$ increases while the concentration profile $\phi(\eta)$ decreases with the increasing in $N b$, also the numer- 

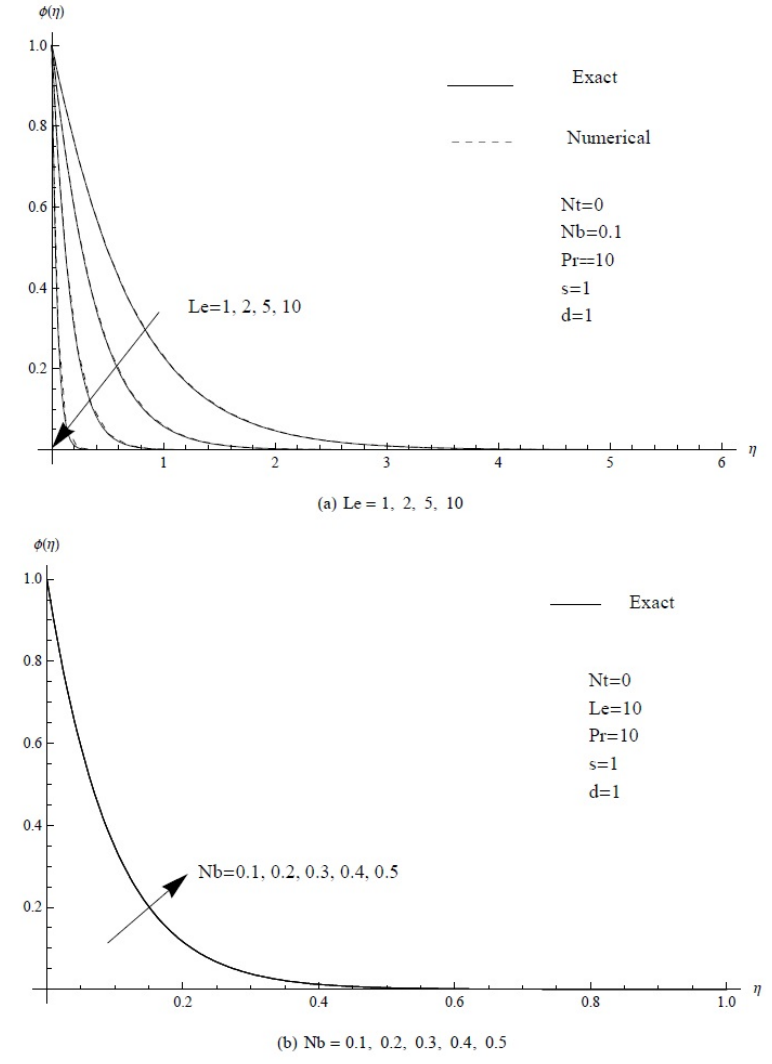

Fig. 3: Effect of $L e$ in (a) and $N b$ in (b) on $\phi(\eta)$.

ical solutions for $\theta(\eta)$ and $\phi(\eta)$ in the case of no effect of the parameter $s$ are agreement with [13]. It is noted that when $L e \succ 1$ the thickness of the thermal boundary layer for the temperature profile $\theta(\eta)$ is bigger than thickness of the boundary layer for the concentration profile $\phi(\eta)$. But with the increase of the parameter $s$ each of the temperature profile $\theta(\eta)$ at $N t=0.1,0.3,0.5$ and the concentration profile $\phi(\eta)$ at $N b=0.1,0.3,0.5$ decrease as shown in Fig. 5.

\section{Conclusion}

New analytical and numerical solutions have been analyzed in absence and presence of thermophoresis for studying the effect of suction or injection on flow of nanofluids past a stretching sheet. In the absence of thermophoresis the analytical exact solution of the stream function was obtained in terms of exponential function, while the exact solutions for temperature and nanoparticle volume fraction obtained in terms of the generalized incomplete gamma function. In the presence of thermophoresis a system of ordinary differential equations
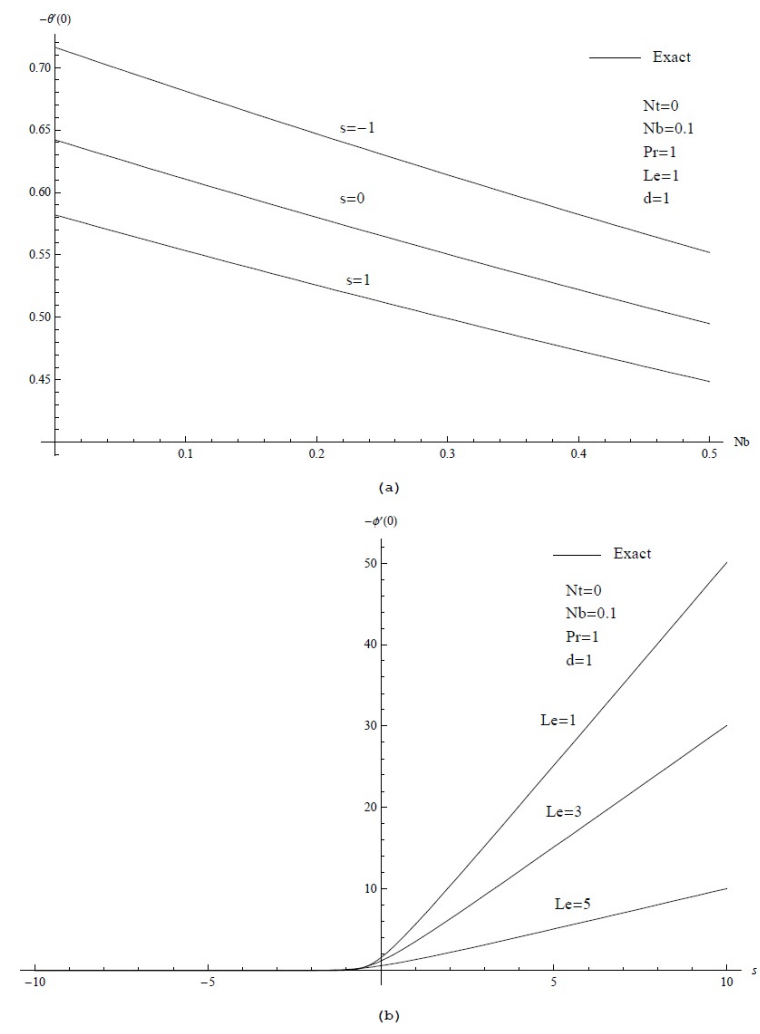

Fig. 4: Effect of $s$ and $N b$ on $-\theta^{\prime}(0)$ in (a) and $s$ and $L e$ on $-\phi^{\prime}(0)$ in (b).

has been solved numerically by using Chebyshev collocation method at some values of the physical parameters; $\mathrm{Pr}, \mathrm{Nb}, \mathrm{Nt}$ and $\mathrm{Le}$. The present numerical results were compared with Khan and Pop [13] for the reduced Nusselt number Nur $=-\theta^{\prime}(0)$ and the reduced Sherwood number $S h r=-\phi^{\prime}(0)$ in tabular forms. It has been concluded from the previous results that:

1. It was found that the present results show good agreement with Khan and Pop [13] and the reduced Nusselt number Nur $=-\theta^{\prime}(0)$ is a decreasing function while the reduced Sherwood number $S h r=-\phi^{\prime}(0)$ is an increasing function.

2. The increase of the parameter $s$ (from injection to suction) decelerates the fluid motion and decreases the temperature and the concentration along a stretching sheet.

3. With increasing in $s=-12,-7,-3$ (injection) and $\operatorname{Pr}$ at $N t=N b=0$ the temperature showed two behavior stages, an increasing stage next to the boundary a decreasing stage far from the boundary as $\eta$ increased but it has only one behavior stage, a decreasing with the increase in $s=0,10$ (suction).

4. The reduced Nusselt number Nur $=-\theta^{\prime}(0)$ increases with the increase in $P r$ and $s$ (for $\mathrm{s} \succ-1$ ) at $N t=N b=$ 


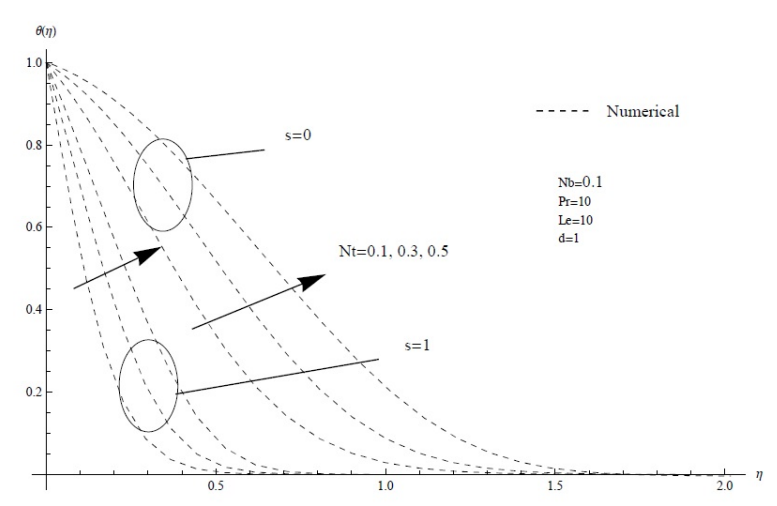

(a)

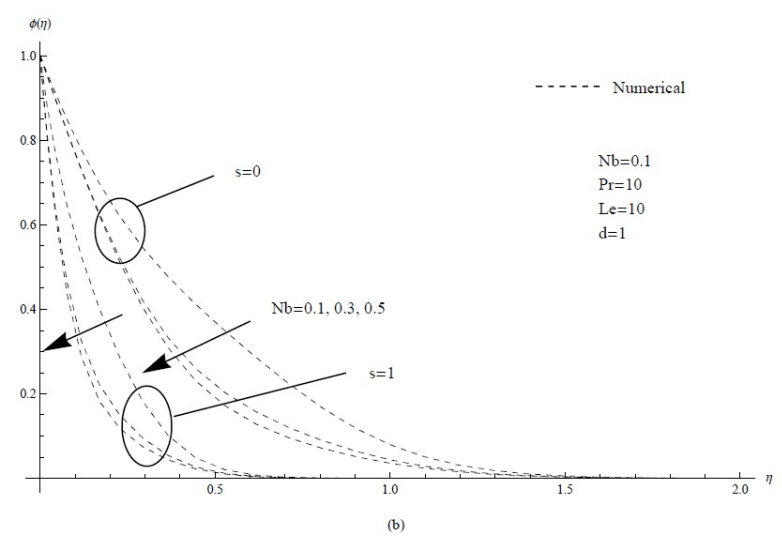

Fig. 5: Effect os $s$ and $N t$ in (a) on $\theta(\eta)$ and $s$ and $N b$ in (b) on $\phi(\eta)$.

0 , but it decreases with the increasing in $\mathrm{Nb}$ and s from -1 to 1 at $N t=0, P r=L e=1$. However, the reduced Sherwood number $S h r=-\phi^{\prime}(0)$ decreases with the increasing in $L e$ and $s$ (for $\mathrm{s} \succ-1$ ) at $N t=0, N b=0.1$ and $P r=1$.

5. Lewis number $L e \succ 1$ has strong effect on the concentration profile $\phi(\eta)$, where an increase in the Lewis number $L e$ the concentration profile $\phi(\eta)$ decreases and also the Brownian motion parameter $\mathrm{Nb}$ has no effect on the concentration profile $\phi(\eta)$.

\section{References}

[1] S.U.S. Choi, Enhancing thermal conductivity of fluids with nanoparticles, The Proceedings of the 1995 ASME International Mechanical Engineering Congress and Exposition, San Francisco, USA, ASME, FED 231/MD, 66 (1995), 99 -105.

[2] S.U.S. Choi, Z.G. Zhang, W. Yu, F.E. Lockwood, E.A. Grulke, Anomalously thermal conductivity enhancement in nanotube suspensions, Appl. Phys. Lett., 79 (2001), 2252 - 2254.
[3] H. Masuda, A. Ebata, K. Teramae, N. Hishinuma, Alterlation of thermal conductivity and viscosity of liquid by dispersing ultra-fine particles (Dispersion of g-Al203, SiO2, and $\mathrm{TiO}_{2}$ ultra-fine particles), Netsu Bussei, 7 (1993), 227 -233.

[4] S. Lee, S.U.S. Choi, S. Li, J.A. Eastman, Measuring thermal conductivity of fluids containing oxide nanoparticles, Trans. ASME, J. Heat Transfer, 121 (1999), 280 - 289.

[5] Y. Xuan, Q. Li, Heat transfer enhancement of nanofluids, Int. J. Heat Fluid Flow, 21 (2000), 58 - 64.

[6] Y. Xuan, W. Roetzel, Conceptions for heat transfer correlation of nanofluids, Int. J. Heat Mass Transfer, 43 (2000), 3701 3707.

[7] S. Kakaç, A. Pramuanjaroenkij, Review of convective heat transfer enhancement with nanofluids, Int. J. Heat Mass Transfer, 52 (2009), 3187-3196.

[8] E. Abu-Nada, Application of nanofluids for heat transfer enhancement of separated flows encountered in a backward facing step, Int. J. Heat Fluid Flow, 29 (2008), 242-249.

[9] H.F. Oztop, E. Abu-Nada, Numerical study of natural convection in partially heated rectangular enclosures filled with nanofluids, Int. J. Heat Fluid Flow, 29 (2008), 1326-1336.

[10] D.A. Nield, A.V. Kuznetsov, The Cheng-Minkowycz problem for natural convective boundary layer flow in a porous medium saturated by a nanofluid, Int. J. Heat Mass Transfer, 52 (2009), 5792-5795.

[11] A.V. Kuznetsov, D.A. Nield, Natural convective boundary-layer flow of a nanofluid past a vertical plate, Int. J. Thermal Sci., 49 (2010), 243-247.

[12] P. S. Gupta and A. S. Gupta, Heat and mass transfer on a stretching sheet with suction or blowing, Can. J. Chem. Eng., 55, pp. 744-746, 1977.

[13] W.A. Khan, I. Pop, Boundary layer flow of a nanofluid past a stretching sheet, International. Journal of Heat and Mass Transfer, 53 (2010), 2477-2483.

[14] L.J. Crane, Flow past a stretching plate, J. Appl. Math. Phys. (ZAMP), 21 (1970), 645 - 647.

[15] Canuto, C., Hussaini, M. Y., and Zang, T. A, Spectral Methods in Fluid Dynamics, Springer-Verlag, New York, (1988).

[16] Peyret, R. (2002). Spectral Methods for Incompressible Viscous Flow, Springer-Verlag, New York.

[17] Nader Y. Abd Elazem, Numerical Solution for Nanofluid Flow Past a Permeable Stretching or Shrinking Sheet with Slip Condition and Radiation Effect, J. Comput. Theor. Nanosci. 12, (2015), 3827-3834.

[18] Nader Y. Abd Elazem, Boundary layer flow of a nanofluid in view of Chebyshev collocation method, International Conference on Applied Mathematics and Sustainable Development -Special track within SCET (2012), Xi'an Technological University, China, May 27-30, http://www.engii.org/scet2012/.

[19] C.Y. Wang, Free convection on a vertical stretching surface, J. Appl. Math. Mech. (ZAMM), 69, (1989) 418-420.

[20] R.S.R. Gorla, I. Sidawi, Free convection on a vertical stretching surface with suction and blowing, Appl. Sci. Res. 52, (1994), 247-257. 